Original article

\title{
Seasonality of thrombogenic disorders in coronary atherosclerosis recrudescence
}

\author{
Svetlana S. Parshina, Tatyana N. Afanasyeva, Liliana K. Tokaeva \\ Saratov State Medical University n.a. V.I. Razumovsky, Saratov, Russia \\ Received 12 August 2012, Revised 5 September 2012, Accepted 10 September 2012.
}

(C) 2012, Parshina S.S., Afanasyeva T.N., Tokaeva L.K.

C 2012, Russian Open Medical Journal

\begin{abstract}
Seasonality of thrombogenic disorders in coronary atherosclerosis recrudescence has been studied using a comparison of blood clotting peculiarities in patients with stable $(n=167)$ and unstable angina $(n=210)$ in different season periods. It was established that there is no common mechanism for decompensation of hemostasis system in progressive angina. The structure of thrombogenic disorders is nonhomogeneous. In winter the most important thing is an activating of prothrombinase producing, and in spring - reducing of heparin content and fibrinolysis activity inhibition. In summer thrombogenic changes are characterized by activating of intrinsic prothrombinase producing mechanism, antithrombin-III decreased activity and heparin content, fibrinolysis activity inhibition. In autumn an advanced euglobulin fibrinolysis block is enough to break the adaptation of hemostasis system.
\end{abstract}

Keywords: atherosclerosis, angina, blood clotting, fibrinolysis, season disorders.

Cite as Parshina SS, Afanasyeva TN, Tokaeva LK. Seasonality of thrombogenic disorders in coronary atherosclerosis recrudescence. Russian Open Medical Journal 2012; 1: 0205

Correspondence to Svetlana S. Parshina. Address: Saratov State Medical University n.a. V.I. Razumovsky, 112, Bolshaya Kasachya str., Saratov, 410012, Russia. E-mail: sargkb12@gmail.com.

\section{Introduction}

Instability of an atherosclerosis plaque and a following clotting cascade disorders causing thrombus formation are the main reason of angina progressing and myocardial infarction development. So this refers to a break of a long and full adaptation $[1,2]$ to hypoxia and development of an emergent adaptation. The emergent adaptation is developed in patients with unstable angina and characterized both by pathogenetic and protective and adaptive reactions. The formation of pathogenetic and protective and adaptive reactions should not be considered separately from environmental factors influence. Today there is extremely little information in available scientific literature $[3,4]$. The most of articles highlight just frequency of acute cases incidence rate (myocardial infarction, acute coronary syndrome) and a severity of symptoms during external natural factors changes.

The research aimed studying of season biorhythms influence on thrombogenic and compensatory mechanisms of hemostasis system during the transition from stable coronary atherosclerosis into unstable.

\section{Material and methods}

Mechanisms of transformation of a long adaptation into the emergent one were evaluated with the help of the comparison hemostasis system condition in 167 patients with stable angina (SA) and 210 patients with progressive angina (PA). Season peculiarities of adaptation transformations were analyzed comparing the rates depending on the time of a year. Patients with newly diagnosed unstable angina were not included into the research.
In SA group in winter there 42 people were examined, 42 people - in spring, 19 people - in summer, 64 people - in autumn. In PA group in winter there 71 people were examined, in spring 39 people, in summer -18 people, in autumn -82 people.

There were 97 healthy people in control group in which ischemic heart disease was excluded using anamnesis and exercise tolerance test. The control group was also examined seasonally (in winter - 25 people, in spring - 23 people, in summer - 19 people, in autumn -30 people).

Age and sex of the people from all of the groups were comparable.

Studying of a procoagulant link of hemostasis system included the determination of an activated partial thromboplastin time (APTT, sec.), blood activated recalcification time (BART, sec.), prothrombin time (PT, sec.) using "Технология-Стандарт" kits ([Tekhnologiya-Standart]) and fibrinogen content (FG, g/l) using R.A. Rutberg unified gravimetric method (1961). To evaluate anticoagulant potential of hemostasis system there following items were performed: antithrombin-III activity (At-III, \%) was studied with the help of the "Tekhnologiya-Standart" universal kit according to U. Abildgaard et al. (1970); endogenic heparin content $(\mathrm{H}, \mathrm{ea} / \mathrm{ml})$ in protamine sulfate titre according to Warren and Vysotsky principle (1965) in G.V. Korshunov's modification (Korshunov G.V., Kirichuk V.F., Guryanov A.I., 1966). Blood plasma fibrinolytic activity was estimated by XIla-kallikrein-dependent euglobulin fibrinolysis (EF, min.) using "Fibrinolysis-test" kit by "Tekhnologiya-Standart". 
Cardiology

Table 1. Comparative analysis of season biorhythms of procoagulant blood activity indicators in patients with stable and progressive angina (M $\pm m$ )

\begin{tabular}{|c|c|c|c|c|c|c|c|c|c|}
\hline \multirow[b]{2}{*}{ Indicators } & \multirow{2}{*}{$\begin{array}{l}\text { IHD } \\
\text { forms }\end{array}$} & \multicolumn{4}{|c|}{ Patients with angina (SA/PA) } & \multicolumn{4}{|c|}{ Control (n=97) } \\
\hline & & $\begin{array}{c}\text { Winter } \\
(n=42 / 71)\end{array}$ & $\begin{array}{c}\text { Spring } \\
(n=42 / 39)\end{array}$ & $\begin{array}{l}\text { Summer } \\
(n=19 / 18)\end{array}$ & $\begin{array}{c}\text { Autumn } \\
(n=64 / 82)\end{array}$ & $\begin{array}{l}\text { Winter } \\
(n=25)\end{array}$ & $\begin{array}{l}\text { Spring } \\
(n=23)\end{array}$ & $\begin{array}{c}\text { Summer } \\
(n=19)\end{array}$ & $\begin{array}{l}\text { Autumn } \\
(n=30)\end{array}$ \\
\hline \multirow{2}{*}{ APTT, s } & SA & $\begin{array}{c}55.2 \pm 8.4 \bullet \\
* \text { autumn }\end{array}$ & $43.1 \pm 2.8 \bullet$ & $44.3 \pm 5.8 \bullet$ & $\begin{array}{c}40.4 \pm 1.2 \bullet \\
* \text { winter }\end{array}$ & \multirow{2}{*}{$32.1 \pm 1.2$} & \multirow{2}{*}{$\begin{array}{l}33.5 \pm 0.8 \\
* \text { autumn }\end{array}$} & \multirow{2}{*}{$29.4 \pm 0.9$} & \multirow{2}{*}{$\begin{array}{l}27.8 \pm 0.9 \\
* \text { spring }\end{array}$} \\
\hline & PA & $41.5 \pm 1.4 \bullet$ & $\begin{array}{l}38.4 \pm 0.9 \bullet \\
\quad * \text { autumn }\end{array}$ & $40.4 \pm 1.9 \bullet$ & $\begin{array}{c}42.2 \pm 0.9 \bullet \\
* \text { spring }\end{array}$ & & & & \\
\hline \multirow{2}{*}{ BART, $s$} & SA & $64.8 \pm 2.5$ & $58.3 \pm 4.1$ & $60.3 \pm 4.3$ & $62.8 \pm 1.3$ & \multirow{2}{*}{$62.5 \pm 1.9$} & \multirow[b]{2}{*}{$\begin{array}{l}63.8 \pm 1.8 \\
* \text { autumn }\end{array}$} & \multirow{2}{*}{$60.7 \pm 1.6$} & \multirow[b]{2}{*}{$\begin{array}{c}59.8 \pm 1.7 \\
* \text { spring }\end{array}$} \\
\hline & PA & $\begin{array}{l}55.2 \pm 1.0 \bullet \\
\quad * \text { autumn }\end{array}$ & $56.7 \pm 1.7 \bullet$ & $56.8 \pm 1.7 \bullet$ & $\begin{array}{l}58.9 \pm 0.9 \\
* \text { winter }\end{array}$ & & & & \\
\hline \multirow[b]{2}{*}{ PT, s } & SA & $15.8 \pm 0.9$ & $16.8 \pm 2.4$ & $\begin{array}{c}18.1 \pm 1.4 \bullet \\
* \text { autumn }\end{array}$ & $\begin{array}{c}14.1 \pm 0.5 \\
\text { * summer }\end{array}$ & \multirow[b]{2}{*}{$\begin{array}{l}15.9 \pm 0.3 \\
* \text { summer }\end{array}$} & \multirow[b]{2}{*}{$\begin{array}{l}16.3 \pm 0.2 \\
* \text { autumn }\end{array}$} & \multirow[b]{2}{*}{$\begin{array}{l}14.9 \pm 0.4 \\
* \text { winter }\end{array}$} & \multirow[b]{2}{*}{$\begin{array}{c}14.2 \pm 0.3 \\
* \text { spring }\end{array}$} \\
\hline & PA & $\begin{array}{c}15.7 \pm 0.4 \\
* \text { summer }\end{array}$ & $15.4 \pm 0.5$ & $\begin{array}{c}14.3 \pm 0.5 \\
* \text { winter } \\
* \text { autumn }\end{array}$ & $\begin{array}{l}16.1 \pm 0.3 \\
\quad * \text { summer }\end{array}$ & & & & \\
\hline \multirow[b]{2}{*}{$\mathrm{FG}, \mathrm{g} / \mathrm{I}$} & SA & $3.64 \pm 0.25 \bullet$ & $3.84 \pm 0.22 \bullet$ & $3.77 \pm 0.63$ & $4.03 \pm 0.20 \bullet$ & \multirow[b]{2}{*}{$\begin{array}{l}3.00 \pm 0.08 \\
* \text { summer }\end{array}$} & \multirow[b]{2}{*}{$\begin{array}{l}2.82 \pm 0.11 \\
* \text { autumn }\end{array}$} & \multirow[b]{2}{*}{$\begin{array}{c}3.29 \pm 0.13 \\
* \text { winter }\end{array}$} & \multirow[b]{2}{*}{$\begin{array}{c}3.33 \pm 0.10 \\
* \text { spring }\end{array}$} \\
\hline & PA & $\begin{array}{c}4.01 \pm 0.12 \bullet \\
* \text { summer }\end{array}$ & $\begin{array}{c}3.92 \pm 0.12 \bullet \\
* \text { summer }\end{array}$ & $\begin{array}{c}3.25 \pm 0.16 \\
* \text { winter } \\
* \text { spring } \\
* \text { autumn }\end{array}$ & $\begin{array}{c}3.86 \pm 0.11 \bullet \\
* \text { summer }\end{array}$ & & & & \\
\hline
\end{tabular}

- - the difference from the control group is statistically significant $(p<0.05),{ }^{*}$ - the difference between seasons is statistically significant ( $\left.<<0.05\right), \bullet-$ the difference between SA and PA groups is statistically significant $(p<0.05)$.

\section{Results}

In winter during the recrudescence of ischemic heart disease an activating of intrinsic prothrombinase producing mechanism is noticed which is characterized by shortening of APTT and BART in patients with PA in comparison with SA group $(p<0.05)$ (Table 1). However, compensatory lengthening of APTT specific to SA is staying the same in comparison with the control group $(p<0.05)$. At the same time in PA BART is shortened in comparison with BART of the control group $(p<0.05)$ while in patients with SA there have not such differences been determined ( $p>0.05)$. The activity of an extrinsic prothrombinase producing mechanism (according to PT rates) and FG content were not different in PA and SA groups ( $p>0.05$ ) (Table 1).

In spring in the break of long adaptation and angina progressing there shortening of APTT $(p<0.05)$ is fixed, which however had been staying long comparing with control point $(p<0.05)$. (Table 1). FG high concentration had been staying without a specific dynamics ( $p>0.05)$, BART and PT had also not been statistically changed ( $p>0.05$ ) (Table 1$)$. In summer time of a year there is an increase of activating of an extrinsic prothrombinase producing mechanism in patients with PA (on a background of normal FG level): a sharp shortening of PT comparing with SA group rates $(p<0.05)($ Table 1$)$. However, an adaptive lengthening of PT (as in patients with SA in summer) as related to the control point has disappeared ( $p>0.05$ with control).

In autumn during the disease progressing a decreased activity of the extrinsic prothrombinase producing mechanism is fixed: lengthening of PT comparing with SA group $(p<0.05)$, however the PT rate is going higher than the same rate in healthy people $(p<0.05)$ (Table 1). The APTT and BART dynamics was not determined ( $p>0.05$ ): APTT keeps being compensatory lengthened compared with control rates $(p<0.05)$; BART in patients with PA does not differ from BART of healthy people $(p>0.05)$ as well as in SA group. There is no hyperfibrinogenemia intensification (typical of patients with SA in autumn) in the disease progressing ( $p>0.05)$ (Table 1).

Therefore, in winter during the coronary atherosclerosis recrudescence the most importance is an activating of intrinsic prothrombinase producing mechanism and decrease of an intensity of compensatory reactions, which are typical of a long hemostasis system adaptation to hypoxia. In spring and summer time of the year the decrease of compensatory reactions of a coagulative link activity is an independent factor of PA pathogenesis even without hypercoagulative changes. Autumn period is characterized by maintenance of previous and forming new compensatory reactions of a coagulative link in hemostasis system.

During the progressing of disease season biorhythms of procoagulate potential rates change sharply in comparison with SA as well as in relation to season biorhythms in healthy people.

There are following peculiarities in season disorders of anticoagulant potential in patients with SA and PA.

In winter disorders in anticoagulant link in hemostasis system are not involved with a failure of a long adaptation mechanisms: At-III value and heparin level in patients with PA and SA do not have statistically accurate differences $(p>0.05)$ (Table 2$)$. However, physiological endogenic heparin level is maintained. At-III activity in patients with PA and SA is reduced in comparison with the control group $(p<0.05)$.

In spring a failure of a long adaptation to hypoxia is caused by a decrease of heparin concentration $(p<0.05)$. However, an increase of At-III activity to the normal degree is fixed in angina progressing comparing with $S A(p<0.05)$ ( $p>0.05$ with control value) (Table 2$)$.

Summer time is characterized by an anticoagulant protection failure in patients with PA (Table 2). The sharp decrease of At-III activity is fixed comparing with $S A$ group $(p<0.05)$ as well as comparing with the control group $(p<0,05)$; dramatic decline of a low heparin baseline in patients with SA $(p<0.05)$. 
Table 2. Comparative analysis of season biorhythms of anticoagulant blood activity indicators and euglobulin fibrinolysis indicators in patients with stable and progressing angina $(\mathrm{M} \pm \mathrm{m})$

\begin{tabular}{|c|c|c|c|c|c|c|c|c|c|}
\hline \multirow{2}{*}{ Indicators } & \multirow{2}{*}{$\begin{array}{l}\text { IHD } \\
\text { forms }\end{array}$} & \multicolumn{4}{|c|}{ Patients with angina (SA/PA) } & \multicolumn{4}{|c|}{ Control (n=97) } \\
\hline & & $\begin{array}{c}\text { Winter } \\
(n=42 / 71)\end{array}$ & $\begin{array}{c}\text { Spring } \\
(n=42 / 39)\end{array}$ & $\begin{array}{l}\text { Summer } \\
(n=19 / 18)\end{array}$ & $\begin{array}{c}\text { Autumn } \\
(n=64 / 82)\end{array}$ & $\begin{array}{l}\text { Winter } \\
(n=25)\end{array}$ & $\begin{array}{l}\text { Spring } \\
(\mathrm{n}=23)\end{array}$ & $\begin{array}{l}\text { Summer } \\
(n=19)\end{array}$ & $\begin{array}{l}\text { Autumn } \\
(n=30)\end{array}$ \\
\hline \multirow{2}{*}{ AT-III, \% } & SA & $79.3 \pm 3.2 \bullet$ & $\begin{array}{c}70.2 \pm 4.16 \bullet \\
* \text { autumn } \\
* \text { summer }\end{array}$ & $\begin{array}{l}87.2 \pm 3.3 \\
* \text { spring }\end{array}$ & $\begin{array}{l}82.8 \pm 3.8 \\
* \text { spring }\end{array}$ & \multirow[b]{2}{*}{$86.7 \pm 2.0$} & \multirow[b]{2}{*}{$89.9 \pm 2.1$} & \multirow[b]{2}{*}{$87.8 \pm 3.4$} & \multirow{2}{*}{$85.9 \pm 2.3$} \\
\hline & PA & $\begin{array}{l}81.6 \pm 2.5 \bullet \\
* \text { spring }\end{array}$ & $\begin{array}{c}89.7 \pm 3.4 \\
* \text { winter } \\
* \text { summer }\end{array}$ & $\begin{array}{l}70.0 \pm 9.6 \bullet \\
* \text { spring }\end{array}$ & $85.6 \pm 2.5$ & & & & \\
\hline \multirow{2}{*}{$\mathrm{H}$, ea/ml } & SA & $6.20 \pm 1.49$ & $\begin{array}{l}9.00 \pm 2.52 \\
\text { * summer }\end{array}$ & $\begin{array}{c}4.67 \pm 0.61 \bullet \\
* \text { spring }\end{array}$ & $6.00 \pm 1.06$ & \multirow[b]{2}{*}{$\begin{array}{l}8.21 \pm 1.14 \\
* \text { summer }\end{array}$} & \multirow[b]{2}{*}{$8.73 \pm 1.19$} & \multirow[b]{2}{*}{$\begin{array}{c}6.52 \pm 0.39 \\
* \text { winter }\end{array}$} & \multirow[b]{2}{*}{$7.31 \pm 0.97$} \\
\hline & PA & $\begin{array}{l}6.00 \pm 0.39 \\
* \text { summer }\end{array}$ & $\begin{array}{l}5.13 \pm 1.52 \bullet \\
* \text { autumn }\end{array}$ & $\begin{array}{c}1.67 \pm 0.67 \bullet \\
* \\
* \text { winter } \\
* \text { autumn }\end{array}$ & $\begin{array}{l}6.63 \pm 0.55 \\
* \text { summer }\end{array}$ & & & & \\
\hline \multirow[b]{2}{*}{$\mathrm{EF}, \min$} & SA & $10.17 \pm 1.58 \bullet$ & $6.50 \pm 1.26$ & $10.32 \pm 2.81$ & $10.00 \pm 1.13 \bullet$ & \multirow[b]{2}{*}{$\begin{array}{l}7.75 \pm 1.11 \\
* \text { summer }\end{array}$} & \multirow[b]{2}{*}{$\begin{array}{l}9.83 \pm 1.36 \\
* \text { autumn }\end{array}$} & \multirow[b]{2}{*}{$\begin{array}{c}6.09 \pm 1.25 \\
* \text { winter } \\
\text { *autumn }\end{array}$} & \multirow[b]{2}{*}{$\begin{array}{c}7.96 \pm 0.21 \\
* \text { spring } \\
\text { * summer }\end{array}$} \\
\hline & PA & $\begin{array}{l}12.52 \pm 1.50 \bullet \\
* \text { spring }\end{array}$ & $\begin{array}{l}9.31 \pm 0.70 \bullet \\
* \text { winter } \\
* \text { summer } \\
* \text { autumn }\end{array}$ & $\begin{array}{l}15.41 \pm 3.22 \bullet \\
* \text { spring }\end{array}$ & $\begin{array}{c}15.11 \pm 1.02 \bullet \\
* \text { spring }\end{array}$ & & & & \\
\hline
\end{tabular}

$\bullet$ - the difference from the control group is statistically significant $(p<0.05),{ }^{*}$ - the difference between seasons is statistically significant ( $\left.<<0.05\right), \bullet-$ the difference between SA and PA groups is statistically significant $(p<0.05)$.

In autumn the failure of hemostasis system long adaptation goes without anticoagulant link: differences between At-III activity and heparin level (Table 2). The given results show that a developing reduction of natural anticoagulants is involved with a failure of a long adaptation in patients with angina only in summer. In winter there is no worsening of disorders of anticoagulant link in ischemic heart disease recrudescence. In spring the developing of the disease is accompanied by paradoxical increase and normalization of the low At-III activity in SA. In autumn the failure of the long adaptation does not involve anticoagulant link.

The failure of a long adaptation mechanisms is accompanied by a disorder in steady season biorhythms of At-III activity and heparin concentration.

The following peculiarities were found out during the analyzing of biorhythms of season euglobulin fibrinolysis activity changes in patients with SA and PA.

In winter the patients with PA and SA had an EF inhibition $(p<0.05)$ which had been staying constant during the disease progress ( $p>0.05$ ) (Table 2 ). In spring in the patients with SA the EF activity had been kept ( $p>0.05$ with control), but during the angina progressing there had a EF blockade been developing (comparing with the control group $(p<0.05)($ Table 2$))$. In summer time the growing of the EF blockade $(p<0.05)$ had also been involved with thrombogenic disorders in angina progressing. In autumn in the patients with stable form of angina the reduction of euglobulin fibrinolysis activity $(p<0.05)$ had been fixed, which was worsening by the disease developing $(p<0.05)$ (Table 2$)$.

Therefore, the increase of a blood fibrinolytic activity disorders is involved with the failure of a long adaptation to hypoxia in spring, summer and autumn.

\section{Discussion}

The results of the study show that in the patients with SA the maximal dynamic stability of hemostasis system is in summer, while in autumn - the maximal instability. So, from a perspective of a season adaptation of hemostasis system, this makes possible to explain the maximal rate of sudden cardiac arrest in the period between autumn and winter [4].

In adaptation failure there is not only worsening of thrombogenic disorders, but defense mechanisms activation, which is typical of any stress-reaction developing $[1,2,5]$. It was found out that the nascency of defense and adaptive reactions of hemostasis system under oxidative stress conditions depends on seasons fluctuations.

In winter during the failure of a long clotting system adaptation we had not revealed defense mechanisms activation of procoagulant, anticoagulant links of hemostasis system and fibrinolysis system. That is why winter period is rather vulnerable. It had been fixed that in spring the At-III activity increases along with thrombogenic disorders during angina developing. In summer as well as in winter there had not been revealed defense mechanisms activation of hemostasis system during angina developing.

Therefore, activation of coagulative mechanisms promotes a failure of a long adaptation of hemostasis system in winter and summer periods, fibrinolysis blockade - in spring, summer and autumn periods. In a failure of a long adaptation native defense mechanisms had been revealed just in spring and autumn periods. They are caused by anticoagulants activity increase.

\section{Conclusions}

The given results offer the possibility to make the following conclusions: 
1. The structure of thrombogenic disorders in coronary atherosclerosis recrudescence (angina developing) is characterized by season inhomogeneity. There is no common mechanism for decompensation of hemostasis system. Each of the seasons is characterized by its own combinations of pathological changes leading to a prethrombotic state.

2. In winter thrombogenic changes in hemostasis system (during angina developing) first of all include an activating of intrinsic prothrombinase producing mechanism. This is accompanied by reduction of an intensity of compensatory reactions, which are typical of hemostasis system in stable angina. Other thrombogenic disorders (hyperfibrinogenemia, reduction of At-III activity, fibrinolysis inhibition, etc.) are not involved with a failure of a long adaptation to hypoxia in winter.

3. In spring the failure of a long adaptation to hypoxia is caused by reduction of heparin content, EF inhibition developing. There is also a reduction of adaptive hypocoagulation in I phase of clotting (according to APTT), which is typical of clotting in spring SA.

4. In summer there should be many pathological mechanisms to break a long adaptation of hemostasis system: vanishing of adaptive suppression of extrinsic prothrombinase producing mechanism (shortening of PT), activating of intrinsic prothrombinase producing mechanism (shortening of BART), At-III activity decrease and heparin content, EF inhibition.

5. In autumn the increasing of EF blockade is enough for a failure of a long hemostasis system adaptation to hypoxia.

6. A failure of an adaptation and angina developing in hemostasis system causes worsening of thrombogenic disorders as well as worsening of defense mechanisms activation, which is also under season fluctuations influence.

\section{Reference}

1. Meyerson FZ, Malyshev IY. Fenomen adaptatsionnoi stabilizatsii structur i zashchita serdtsa [The phenomenon of adaptative structure stabilization and heart protection]. Nauka, Moscow, Russia, 1993. $159 \mathrm{p}$.

2. Meyerson FZ. Dolgovremennaya adaptatsiya i adaptatsionnaya zashchita organizma ot povrezhdeniya [Long adaptation and organism defense from defects]. Meditsina, Moscow, Russia, 1997: 327-334.

3. Baluda VP, Isabayeva VA, Ponomaryova TA, Adamchik AS. Biologicheskiye ritmy sistemy gemostaza cheloveka [Biological rhythms in human hemostasis system]. Ilim, Frunze, USSR, 1978. 197 p.

4. Khronobiologya i khronomeditsina [Chronobiology and chronomedicine], edited by Komarov F.I. Meditsina, Moscow, USSR, 1989. $400 \mathrm{p}$.

5. Malyshev IY, Manukhina YB. Stress, adaptatsiya i oksid azota [Stress, adaptation and nitric oxide]. Biokhimiya [Biochemistry] 1998; 63(7): 992-1006.

\section{Authors:}

Svetlana S. Parshina - MD, D.Sc., Professor, Department of Therapy, Faculty training and retraining of specialits, Saratov State Medical University n.a. V.I. Razumovsky, Saratov, Russia;

Tatyana N. Afanasyeva - MD, PhD, Assistant, Department of Therapy, Faculty training and retraining of specialits, Saratov State Medical University n.a. V.I. Razumovsky, Saratov, Russia; Chair of therapy of the FIQ PTS Saratov State Medical University named after V.I. Razumovsky

Liliana K. Tokaeva - MD, D.Sc., Professor, Department of Normal Physiology, Saratov State Medical University n.a. V.I. Razumovsky, Saratov, Russia. 